\title{
Legislativo municipal, organização partidária e coligações partidárias
}

\author{
Maria Teresa Miceli Kerbauy ${ }^{1}$
}

RESUMO: O objetivo deste artigo é analisar a relação entre o sistema partidário local e o Legislativo Municipal, bem como dimensionar a importância das organizações partidárias locais. O entendimento de como funciona o sistema partidário local e o papel que exerce na relação Executivo/Legislativo contribuem para uma melhor explicação de como as preferências políticas se distribuem entre os representantes locais e quais as consequências das mesmas para a democratização do governo local.

PALAVRAS-CHAVE: Organizações partidárias, legislativo municipal, coligações partidárias.

ABSTRACT: The objective of this paper is to analyze the relation between local party system and Municipal Legislative, as well as to give a dimension for the importance of the local parties organization. A most proper understanding on how the local party system works and on its role over the relation Executive/Legislative collaborates for a better explanation of how the political preferences are spread out among local representatives and the consequences of these preferences on the local government democratization.

KEYWORDS: Party organization, municipal legislative and parties, colligations.

${ }^{1}$ Professora do programa de pós-graduação em Sociologia da Universidade Estadual Paulista. Campus Araraquara, Rodovia Araraquara-Jaú, Km 1, Araraquara - SP, 1480-901. E-mail: kerbauy@travelnet.com.br. 


\section{Introdução}

Apesar dos estudos sobre poder legislativo no Brasil terem acumulado importantes avanços, poucos se dedicaram a analisar a atuação do Legislativo Municipal, às regras que determinam o processo de interação dos poderes Executivo e Legislativo, às formas como se orientam as ações dos atores políticos do Legislativo local e ao papel desempenhado pelo sistema eleitoral e partidário na constituição e atuação dos Legislativos Municipais.

O objetivo deste trabalho é analisar a relação entre o sistema partidário local e o Legislativo Municipal, assim como dimensionar a importância das organizações partidárias locais. Os poucos estudos que se debruçaram sobre o papel das Câmaras Municipais na arena eleitoral valeram-se em geral, do argumento da fragilidade dos partidos políticos e do papel das legendas no atendimento de projetos pessoais. Poucos enfocaram o papel das organizações partidárias nas eleições municipais e, menos ainda, o papel da arena eleitoral na constituição da relação Legislativo/Executivo como forma de garantir a governabilidade local e não apenas a garantia de benefícios localizados e individualistas.

Segundo Ames (2003) as instituições políticas criam incentivos para estimular os políticos a maximizarem seus ganhos pessoais e a se concentrarem em obter projetos de obras públicas para eleitores localizados. O legislativo municipal seria o exemplo mais extremado dessa situação, ao exagerar a orientação individualista e fisiológica desempenhada pelos vereadores, em detrimento do impacto dos partidos políticos na arena eleitoral local.

A patronagem exerceria um papel importante neste processo, pois o conjunto de recursos à disposição do Executivo local induziria os vereadores a aprovarem a agenda política do prefeito independentemente do partido e da forma como o sistema partidário está estruturado no município. As regras eleitorais que já produziriam efeitos negativos na representação do Congresso e das Assembléias Estaduais teriam seu efeito acentuado nos legislativos nos municípios.

Apesar de alguns autores que trabalham com a variável sistema eleitoral e sistema partidário apontarem para a importância das organizações partidárias locais para as eleições presidenciais (AMES, 1994) e para o legislativo federal (PEREIRA e RENNÓ, 2001) não existem análises sobre a relação entre o sistema partidário e as Câmaras Municipais e a decorrente conexão 
eleitoral, pois o foco da análise destes autores está na esfera federal e de como as orientações localistas interferem no sistema partidário nacional.

Em direção contrária a essa análise, Figueiredo e Limongi (1999) e Amorin Neto e Santos (2001) questionam esse consenso, tomando como base os efeitos da centralização decisional e os poderes de legislar do presidente brasileiro e afirmam que o comportamento dos parlamentares no Congresso não aponta para a fraqueza ou fragmentação do nosso sistema partidário. Os partidos estariam aptos a resolverem problemas de ação coletiva especialmente aos líderes dos partidos e aqueles que desempenham papel chave no processo decisório (SANTOS, 2008).

A análise do processo legislativo utilizada por estes autores:

“[...] lança luz sobre a natureza da prática legislativa dos deputados, cuja tensão assenta entre a prática clientelista/paroquial ou nacional. Amorin Neto (2000), Santos (2002), acompanhados por Ricci (2003) assumem que os recursos de patronagem e as características próprias do processo legislativo dão certa margem a negociações permanentes no Congresso e que este processo de negociação é parte da explicação do funcionamento do legislativo brasileiro" (SANTOS, 2008: 9).

Caetano (2005) em um dos poucos estudos sobre a existência de incentivos à ação partidária no Legislativo Municipal, considera o respeito que, no momento da votação, os parlamentares têm à orientação dos líderes dos partidos aos quais estão filiados, o que os constrangem a atuarem em bases partidárias.

Ao contrário do que mostram os estudos feitos para as esferas federal e estadual, indicando a recuperação da importância dos partidos, as pesquisas realizadas na esfera local apontam para o desprestígio da função de coordenação exercida pelos partidos, ao mesmo tempo em que se ressalta a atuação do prefeito como o maior detentor do processo legislativo, ao tomar a iniciativa de projetos de lei, sendo o responsável por individualizar a negociação política e desconsiderar totalmente o papel da organização partidária.

A aplicação dos modelos teóricos sobre o legislativo nas análises sobre o legislativo municipal esbarra no problema de escala. De acordo com a legislação eleitoral, o número de vereadores é proporcional ao número de habitantes do município. O Brasil tem hoje 5.563 municípios dos 
quais 1.363 foram criados a partir de 1989, graças às regras flexíveis estabelecidas pelo artigo 18, $\S 4^{\circ}$, da Constituição de 1988 definidas para preservar "a continuidade e unidade históricocultural do ambiente urbano, obedecidos os requisitos previstos em lei complementar estadual e mediante consulta prévia ás populações diretamente envolvidas”. O resultado visível do aumento do número de municípios na última década é o fato de $90 \%$ de eles terem menos de 50 mil habitantes e 80\% de suas despesas ser cobertas por transferências institucionais.

Em 1996, a Emenda Constitucional 15, suspendeu a prerrogativa dos Estados de criar municípios. Cinquenta e sete cidades criadas entre 1996 e 2007 dependem de aprovação para deixarem de ser virtuais. Em novembro de 2008 vence o prazo dado para o Supremo Tribunal Federal (STF) para regulamentar esta emenda. Em 24 assembléias legislativas tramitam propostas para a criação de 806 municípios. Se todas forem aceitas o Brasil passará a ter 6.368 prefeitos e um número adicional de 7,2 mil vereadores.

Diante deste impasse foi aprovada pela Comissão de Constituição e Justiça do Senado uma Proposta de Emenda Constitucional (PEC) que devolve aos Estados a competência para criar municípios.A proposta estabelece um mínimo de habitantes para os novos municípios: 5 mil nas Regiões Norte e Centro-Oeste, 7 mil no Nordeste e 10 mil no Sul e Sudeste.Paralelamente a Câmara dos Deputados aprovou no primeiro semestre, em primeiro turno, por ampla maioria, emenda constitucional que autoriza o aumento de 7.554 vereadores, em todo o Brasil. A justificativa para a apresentação do Projeto de Emenda Constitucional foi a correção da determinação da Constituição de 1988 que deu à Lei Orgânica de cada município a prerrogativa de definir o número de vereadores, proporcional à população; dentro de três faixas de limites mínimos e máximos, propiciando ás Câmaras Municipais fixarem o número máximo de leis sem levar em conta o princípio da proporcionalidade da população.

Em 2004, o Supremo Tribunal Federal (STF) considerou que o princípio da proporcionalidade era imperativo e adotou a fórmula de um vereador para cada grupo de 47.619 habitantes, reduzindo 8.528 vagas, na regulamentação das eleições municipais daquele ano.

A emenda Constitucional aprovada em primeira instância fixa o número mínimo de 9 cadeiras para municípios com até 15 mil habitantes e o máximo de 55 para município com mais de 8.000 milhões de habitantes, permitindo o aumento de até 9.000 vereadores em todo o país se o teto máximo estabelecido nas escalas de cadeiras/número de habitantes for aplicado. O projeto 
aprovado pela Câmara vai além do aumento de vagas nas edilidades, reduz o limite de repasses das prefeituras para as Câmaras Municipais de 5\% a 8\% da receita do município para 2\% a 4,75\%, sendo que a variação é determinada pela receita e não pela população.

A dimensão numérica da representação das Câmaras Municipais no Brasil interfere no escopo de uma análise mais ampla. Grande parte dos estudos escolhe como objeto as capitais dos estados. Outros focam a análise nos municípios com mais de 200 mil habitantes. Tanto em um caso quanto no outro, trabalha-se com um universo de vereadores maior (entre 19 e 21) por município e com a possibilidade de $2^{\circ}$ turno de acordo com as regras eleitorais. Existem estudos que trabalham com municípios entre 50 e 100 mil habitantes, ou ainda, estudos de caso que muitas vezes são difíceis de serem generalizados. A magnitude eleitoral regional também deve ser computada. Os estados do Norte e do Centro-Oeste são aqueles com o menor número de municípios e, consequentemente, com o menor número de vereadores. A Tabela 1 mostra a dimensão desta diferença com base no tamanho do eleitorado.

Tabela 1 - Distribuição dos votos para vereador, por região - Brasil (1996, 2000 e 2004)

\begin{tabular}{|c|c|c|c|c|c|c|}
\hline Região & $\mathbf{1 9 9 6}$ & $\mathbf{\%}$ & $\mathbf{2 0 0 0}$ & $\mathbf{\%}$ & $\mathbf{2 0 0 4}$ & $\mathbf{\%}$ \\
\hline Norte & 3.881 .584 & 5,46 & 5.512 .649 & 6,37 & 6.153 .128 & 6,98 \\
\hline Nordeste & 17.836 .749 & 25,13 & 22.737 .176 & 26,32 & 24.265 .682 & 27,53 \\
\hline Sudeste & 32.196 .381 & 45,37 & 38.885 .744 & 44,99 & 38.058 .194 & 43,18 \\
\hline Sul & 12.670 .980 & 17,85 & 13.948 .644 & 16,15 & 14.435 .036 & 18,26 \\
\hline Centro-Oeste & 4.392 .527 & 6,18 & 5.329 .433 & 6,17 & 5.209 .640 & 5,91 \\
\hline Total & 70.978 .221 & 100,00 & 86.413 .643 & 100,00 & 88.121 .680 & 100,00 \\
\hline
\end{tabular}

Fonte: TSE - Tribunal Superior Eleitoral

Um projeto que dê conta da magnitude do número de vereadores que o Brasil possui, das especificidades do sistema partidário, das características deste universo e das dificuldades na construção de uma análise temporal exige a formação de uma rede de pesquisadores envolvidos com o tema. 


\section{Nota sobre a metodologia}

Para esta análise foi realizada uma revisão bibliográfica que procurou dar conta das inúmeras discussões sobre o tema e que permitiu construir um marco interpretativo para os dados empíricos levantados.

A análise da arena eleitoral foi realizada através dos dados disponibilizados pelo TSE para as eleições dos legislativos municipais, no período de 1996, 2000, 2004.

A utilização dos indicadores demográficos municipais, do IBGE, possibilitou um melhor entendimento das diferenças populacionais dos municípios.

\section{Organização Partidária}

Analisar a relação executivo/legislativo na perspectiva da arena eleitoral pode implicar no entendimento das regras eleitorais e suas prováveis consequências para o comportamento individualista dos vereadores, quase sempre interessados na distribuição de benefícios localizados em busca de votos.

Nesta perspectiva a patronagem e o clientelismo caracterizariam o legislativo local, transformando-o em instituições homologadoras das decisões dos prefeitos, nas quais as transferências de recursos individualizados garantem a reeleição dos vereadores e a permanência de um círculo vicioso da política local, regido pelo mandonismo, pelo clientelismo e pelo paternalismo e pela hipertrofia do poder executivo, com relações de dependência político partidária dos governos locais para com os governos estaduais (SOUZA, 2004). O legislativo estaria caracterizado como um mercado de votos.

Ao se dar atenção às estas variáveis o papel dos partidos e das características dos sistemas partidários locais é pouco enfatizada. A alta fragmentação partidária decorrente das regras eleitorais, a natureza federativa do sistema político, a influência do governador e de seu partido na organização partidária local apontam para o desprestígio da função de coordenação exercida pelos partidos, ao mesmo tempo em que ressalta a atuação do prefeito como o maior detentor de poder no processo legislativo, responsável por individualizar a negociação política e desconsiderar totalmente o papel da organização partidária, independentemente do tamanho do município. 
O número de partidos com representação local de acordo com a Tabela 2 indica a fragmentação partidária no Brasil, e os efeitos marcantes no processo eleitoral municipal.

Tabela 2 - Vereadores Eleitos, por partido - Brasil (1996, 2000 e 2004)

\begin{tabular}{lcccccc}
\hline \multicolumn{1}{c}{ Partidos } & $\mathbf{1 9 9 6}$ & $\mathbf{\%}$ & $\mathbf{2 0 0 0}$ & $\mathbf{\%}$ & $\mathbf{2 0 0 4}$ & $\mathbf{\%}$ \\
\hline PPB & 6.238 & 13,14 & 6,805 & 12,27 & 0 & 0,00 \\
PDT & 3.311 & 6,97 & 3.332 & 6,01 & 3.252 & 6,28 \\
PT & 1.546 & 3,26 & 2.234 & 4,03 & 3.679 & 7,10 \\
PTB & 3.029 & 6,38 & 4.450 & 8,02 & 4.176 & 8,06 \\
PMDB & 11.389 & 23,99 & 10.647 & 19,19 & 7.399 & 14,28 \\
PSTU & 0 & 0,00 & 2 & 0,00 & 902 & 1,74 \\
PSL & 260 & 0,55 & 429 & 0,77 & 506 & 0,98 \\
PST & 148 & 0,31 & 359 & 0,65 & 0 & 0,00 \\
PTN & 25 & 0,05 & 80 & 0,14 & 0 & 0,00 \\
PSC & 561 & 1,18 & 646 & 1,16 & 724 & 1,40 \\
PCB & 0 & 0,00 & 2 & 0,00 & 60 & 0,12 \\
PL & 2.350 & 4,95 & 2.490 & 4,49 & 3.806 & 7,34 \\
PPS & 384 & 0,81 & 2.292 & 4,13 & 2.745 & 5,30 \\
PFL & 8.164 & 17,19 & 9.050 & 16,31 & 6.076 & 11,73 \\
PAN & 2 & 0,00 & 29 & 0,05 & 84 & 0,16 \\
PSDC & 55 & 0,12 & 212 & 0,38 & 826 & 1,59 \\
PRTB & 21 & 0,04 & 198 & 0,36 & 228 & 0,44 \\
PCO & 0 & 0,00 & 0 & 0,00 & 12 & 0,02 \\
PGT & 3 & 0,01 & 28 & 0,05 & 0 & 0,00 \\
PSN/PHS & 7 & 0,01 & 110 & 0,20 & 346 & 0,67 \\
PMN & 332 & 0,70 & 318 & 0,57 & 519 & 1,00 \\
PRN & 51 & 0,11 & 56 & 0,10 & 0 & 0,00 \\
PSB & 956 & 2,01 & 1.553 & 2,80 & 1.805 & 3,48 \\
PSD & 1.173 & 2,47 & 1.472 & 2,65 & 0 & 0,00 \\
PV & 164 & 0,35 & 310 & 0,56 & 782 & 1,51 \\
PRP & 340 & 0,72 & 391 & 0,70 & 596 & 1,15 \\
PSDB & 6.754 & 14,22 & 7.690 & 13,86 & 6.566 & 12,67 \\
PRONA & 33 & 0,07 & 26 & 0,05 & 131 & 0,25 \\
PC do B & 86 & 0,18 & 138 & 0,25 & 273 & 0,53 \\
PT do B & 100 & 0,21 & 134 & 0,24 & 317 & 0,61 \\
PP & 0 & 0,00 & 0 & 0,00 & 5.457 & 10,53 \\
PTC & 0,00 & 0 & 0,00 & 310 & 0,60 \\
\hline Total & $\mathbf{4 . 4 8 2}$ & $\mathbf{1 0 0 , 0 0}$ & $\mathbf{5 5 . 4 8 3}$ & $\mathbf{1 0 0 , 0 0}$ & $\mathbf{5 1 . 8 1 9}$ & $\mathbf{1 0 0 , 0 0}$ \\
*Nas eleições de 2000, houve & $17 \%$ de aumento nas cadeiras e, em 2004, o número de vereadores foi reduzido \\
pelo TSE. & & & & & & \\
Fonte: TSE Tribunal Superior Eleitoral & & & & & \\
& & & & & &
\end{tabular}

Os dados da Tabela 2 mostram que o PMDB tem sido o partido que mais elege vereadores no país, apesar de ter havido uma queda na eleição de 2004, refletindo uma significativa capilaridade e a importância da organização partidária. As outras forças partidárias bem representadas são o 
PFL, o PSDB e o PPB (PP), partidos que também sofreram perdas significativas de participação na eleição de 2004. Ao mesmo tempo, tiveram aumento as bancadas de vereadores eleitos pelo PT, PL, PPS e PSB. A novidade é o crescimento de bancada de vereadores do PV, que passou de 0,56\% em 2000, para 1,51\%, em 2004.

Quando se atenta para as diferenças regionais na votação dos partidos, o argumento explicativo remete às dinâmicas estaduais das legendas que interferem no alinhamento entre os partidos políticos nas disputas municipais (DANTAS, 2008).

Analisando-se as eleições para vereador no período 1996, 2000 e 2004, o PMDB foi o partido com o maior número de vereadores eleitos nas regiões Norte, Sudeste, Sul e Centro-Oeste nas eleições 1996/2000. Nas eleições de 2004, perde representação significativa no Norte e no Sudeste; apesar de crescer na região Centro-Oeste não consegue ultrapassar o PSDB. Na região Nordeste, o PFL reúne uma bancada maior do que a do PMDB. Nas outras regiões, os bons resultados eleitorais obtidos pelo PFL apontam para uma capilaridade a ser considerada.

O PSDB foi o segundo partido nas eleições 1996/2000, com maior votação para o legislativo municipal nos estados das regiões Norte, Nordeste e Sudeste, perdendo para o PFL nas regiões Sul e Centro-Oeste. Nas eleições de 2004, o PSDB foi o partido que mais elegeu vereadores no Norte, no Sudeste e no Centro-Oeste.

O PPB (PP) se sobressai nas regiões Norte e Sul em 1996 e em 2000, em Centro-Oeste em 2004. O PTB teve um desempenho mais homogêneo em todas as regiões, conseguindo aumentar significativamente sua votação na região Centro-Oeste, na eleição de 2004.

Para o PT, os desempenhos mais baixos foram localizados nas regiões Nordeste e Centro-Oeste nas eleições de 1996 e 2000; em 2004, o desempenho foi mais equilibrado em todas as regiões.

Para o PT, os desempenhos mais baixos foram localizados nas regiões Nordeste e Centro-Oeste nas eleições de 1996 e 2000; em 2004, o desempenho foi mais equilibrado em todas as regiões.

O PFL, o PPS e o PSB mostraram um aumento tendencial do número de vereadores nas eleições de 1996 e 2000. Em 2004, o PFL só cresceu na região Centro-Oeste.

Focalizando as regiões, em 2004 a região Nordeste manteve a tendência de votação das outras eleições, e o Sul foi a região que mais diferenças apresentou. Nele, o PSTU (8,12\%) e o PSDC (4,12\%) conseguiram ultrapassar a votação do PPS e PSB. Apesar da queda significativa de votos 
do PMDB e do PP, continuaram sendo os partidos mais votados. O PDT encontrou sua maior expressão nesta região.

Apesar da heterogeneidade e das oscilações regionais nas conquistas eleitorais os dados consolidados apontam que dez são os partidos mais votados no Brasil, segundo a Tabela 3. 
Tabela 3 - Vereadores eleitos e partidos mais votados, por região - Brasil (1996, 2000 e 2004)

\begin{tabular}{|c|c|c|c|c|c|c|c|c|c|c|c|c|c|c|c|}
\hline \multirow{2}{*}{$\begin{array}{c}\text { Região } \\
\text { Partidos }\end{array}$} & \multicolumn{3}{|c|}{ Norte $\%$} & \multicolumn{3}{|c|}{ Nordeste \% } & \multicolumn{3}{|c|}{ Sudeste \% } & \multicolumn{3}{|c|}{ Sul \% } & \multicolumn{3}{|c|}{ Centro-Oeste \% } \\
\hline & 1996 & 2000 & 2004 & 1996 & 2000 & 2004 & 1996 & 2000 & 2004 & 1996 & 2000 & 2004 & 1996 & 2000 & 2004 \\
\hline PDT & 4,56 & 4,04 & 4,97 & 5,04 & 4,39 & 4,53 & 4,43 & 4,90 & 5,92 & 15,70 & 9,54 & 10,60 & 0,50 & 0,70 & 4,53 \\
\hline PFL & 19,99 & 10,73 & 11,32 & 22,00 & 19,24 & 16,51 & 19,47 & 13,92 & 11,89 & 12,30 & 12,86 & 4,88 & 6,61 & 8,30 & 10,57 \\
\hline $\mathrm{PL}$ & 2,98 & 5,58 & 9,60 & 5,97 & 5,19 & 7,71 & 5,21 & 4,70 & 8,86 & 1,33 & 0,94 & 2,20 & 4,47 & 2,70 & 11,25 \\
\hline PMDB & 19,62 & 25,05 & 11,78 & 18,49 & 17,12 & 12,89 & 15,98 & 17,72 & 13,49 & 30,13 & 25,76 & 18,45 & 19,24 & 11,38 & 14,33 \\
\hline PPB (PP) & 17,04 & 14,20 & 8,53 & 8,48 & 8,98 & 8,50 & 9,72 & 7,65 & 7,68 & 22,62 & 23,20 & 19,40 & 8,01 & 5,96 & 10,39 \\
\hline PPS & 0,92 & 2,69 & 5,40 & 1,91 & 5,07 & 5,32 & 0,78 & 5,34 & 5,69 & 0,08 & 1,52 & 3,26 & 0,03 & 2,52 & 8,89 \\
\hline PSB & 2,72 & 2,05 & 3,92 & 4,42 & 3,93 & 4,80 & 1,96 & 4,07 & 3,36 & 0,45 & 1,52 & & 0,11 & 0,20 & 2,29 \\
\hline PSDB & 14,64 & 12,67 & 13,07 & 15,26 & 15,02 & 11,58 & 21,58 & 15,45 & 15,57 & 6,30 & 9,69 & 8,84 & 5,95 & 8,05 & 15,59 \\
\hline $\mathrm{PT}$ & 3,45 & 4,16 & 9,77 & 1,68 & 1,94 & 4,33 & 3,15 & 4,89 & 7,69 & 5,04 & 5,95 & 8,97 & 1,19 & 1,13 & 8,24 \\
\hline PTB & 6,94 & 7,29 & 9,15 & 6,08 & 6,97 & 7,33 & 7,87 & 9,28 & 10,01 & 4,80 & 5,42 & 6,17 & 1,32 & 1,90 & 7,44 \\
\hline $\begin{array}{c}\text { Total de } \\
\text { Vereadores }\end{array}$ & 4.455 & 4.862 & 4.186 & 14.687 & 17.823 & 16.539 & 15.518 & 18.678 & 15.842 & 11.112 & 12.135 & 10.967 & 1.710 & 1.986 & 4.285 \\
\hline
\end{tabular}

Fonte: TSE - Tribunal Superior Eleitoral 
A fragmentação partidária incentivada pelo sistema eleitoral (LAMOUNIER e MENEGUELLO, 1986; KINZO, 1993; MAINWANING, 2001) explicaria a fragilidade dos atores partidários influenciando os padrões de votação dos deputados federais e estaduais, sendo o legislativo visto como mercado de votos cujas instituições garantem os ganhos de troca, tendo como moeda corrente os benefícios localizados.

No legislativo municipal estes atributos são exacerbados, com os vereadores adotando um comportamento individualista em troca da distribuição de benefícios, transformando a relação executivo-legislativo municipal num mero balcão de negócios, onde os partidos são desvalorizados.

Mesmo adotando-se a perspectiva de análise da arena executivo-legislativo, para o legislativo municipal, pelo quase consenso de que os partidos não têm nenhum papel no processo de centralização decisório e nem o executivo, especialmente os dos pequenos municípios, possuem poderes presidenciais, fica difícil operacionalizar este tipo de análise na esfera local.

Novamente o desconhecimento sobre os sistemas partidários locais impede uma análise mais adequada sobre a relação executivo/legislativo local. Trabalhos como os de Carneiro e Almeida (2005), sobre migrações partidárias locais, Noll e Leal (2008), sobre carreiras políticas de vereadores, Braga e Borges (2008), sobre organização partidária local e processo de filiação, Machado e Miguel (2008) e Dantas (2008), sobre coligações partidárias locais, apontam alguns caminhos para a análise da relação Executivo-Legislativo local. Poucos estudos analisam a estrutura organizativa dos legislativos municipais especialmente os regimentos internos das Câmaras Municipais, ou ainda, a construção de carreiras ao legislativo municipal.

\section{Coligações Eleitorais Municipais}

A premissa da fragmentação partidária no Brasil encontra respaldo na observação da prática de coligações eleitorais. A análise deste fenômeno nas eleições proporcionais mereceu a atenção de vários autores: Soares (1973), Souza (1990), Lima Jr. (1983) e Lavareda (1991), especialmente para os cenários federal e estadual.

Pouca atenção se deu às coligações eleitorais na esfera municipal. Nas poucas vezes em que são mencionadas, consideram-se como estratégias pessoais dos candidatos a vereadores, sem nenhum 
copartidário. Segundo Lavareda (1991: 20), a eleição proporcional é apenas uma das faces do jogo político. “Os partidos são bem-vindos nas alianças e coligações proporcionais, desde que, em contrapartida, colaborem na sustentação dos candidatos majoritários, lançados pelos grandes partidos. Esse apoio se traduz em recursos humanos e econômicos para a campanha eleitoral, e em aumento do tempo de propaganda eleitoral gratuita nos meios de comunicação”. Isso assegura aos municípios mais governabilidade, uma vez que garante ao prefeito eleito maioria na Câmara Municipal. A suposta racionalidade percebida nas coligações eleitorais constitui um aspecto do comportamento partidário, que visa a maximizar o apoio eleitoral.

A hipótese de Lima Jr. (1983) é de que a disposição aliancista é controlada pelo contexto da competição política em cada cenário estadual. Segundo ele, isto teria reflexo nas eleições para o Executivo-Legislativo municipal, construindo-se uma cadeia de interesses e apoios partidários, da qual as eleições para a Câmara Municipal constituiriam um elo importante.

A análise da estrutura partidária de municípios de três estados brasileiros: Alagoas, Santa Catarina e São Paulo (KERBAUY, 2008) apontam para as diferenças regionais entre eles. Nos municípios de Alagoas, além de a representação partidária ser mais pulverizada, os partidos médios dividem o legislativo com os grandes partidos: PTB, PSB (partido do governador), PDT, PSDB e PMDB. O PT tem pouca expressão nas Câmaras Municipais de Alagoas.

Em Santa Catarina a representação partidária é mais concentrada, e os partidos de maior expressão são PMDB (partido do governador), PFL, PPB/PP e PSDB. Os pequenos partidos ocupam pouco espaço na arena eleitoral.

São Paulo é o Estado onde se verifica a maior pulverização partidária. Apesar disto, os grandes partidos têm uma representação significativa: PSDB (partido do governador) tem a maior representação, seguido pelo PT, PFL, PMDB e PPB/PP.

A competição entre PSDB e PT é nítida em São Paulo, como se pode observar pela análise da base partidária dos vereadores neste estado - um fato que não se repete nos outros estados estudados.

A representação partidária nos legislativos locais, nos estados analisados mantém relação estreita com a representação partidária dos executivos locais e estaduais, apontando para a importância e a influência dos partidos aos quais se filiam os executivos locais e estaduais nas eleições para as Câmaras Municipais. O caso de Alagoas é emblemático, pois o PSB, partido do governador, 
apesar de não ter uma grande expressão nacional, consegue eleger um número significativo de vereadores.

\section{Conclusão}

De maneira geral e nos três estados, os grandes partidos (PMDB, PSDB, PT e PFL) tem maiorias expressivas nas Câmaras Municipais, seguidos pelo PPB/PP, PTB e PDT. Isto nos permite supor que há uma coordenação partidária nesta esfera, fato que aponta para a existência de uma competição efetiva.

O que se pode observar também é que os prefeitos são, em sua maioria, filiados a partidos nacionalmente relevantes. São eles os que mais se beneficiam das coligações para o Executivo local, o que aponta para um complexo jogo de coordenação eleitoral, que passa pa mesmo tempo pelas competições municipal, estadual e federal. Esse jogo fortalece e nacionaliza os grandes partidos a partir da capilaridade municipal, contribuindo para garantir vantagens competitivas, nas disputas majoritárias, para um número reduzido de legendas (BRAGA, 2006: 244).

Qual a lógica das coligações para o Executivo local? Uma explicação poderia ser que, nas eleições majoritárias, os partidos menores oferecem aos seus parceiros: votos, apoio logístico, apoio organizacional e mais tempo no horário eleitoral gratuito.

Como se pode observar pelos dados da Tabela 4, a seguir, um número reduzido de legendas pode garantir vantagens competitivas nas eleições majoritárias, mas não é suficiente para garantir a maioria da representação nas eleições proporcionais. 
Tabela 4 - Tamanho dos Partidos e Candidatos a Vereador eleitos pela coligação do Prefeito Alagoas, Santa Catarina, São Paulo - 2004

\begin{tabular}{|c|c|c|c|}
\hline $\begin{array}{lr}\text { Partidos } & \text { Estado } \\
\end{array}$ & Alagoas & Santa Catarina & São Paulo \\
\hline Grande & $\begin{array}{lr}3 & 8,82 \% \\
\text { PMDB, } & \text { PSDB }\end{array}$ & $\begin{array}{lr}14 & 15,38 \% \\
\text { PMDB, } & \text { PT, PSDB }\end{array}$ & $\begin{array}{lr}27 & 13,63 \% \\
\text { PSDB, } & \text { PMDB, PFL }\end{array}$ \\
\hline Médios & $\begin{array}{cc}10 & 29,41 \% \\
\text { PTB, PL, PPS, PDT, PSB }\end{array}$ & $\begin{array}{cc}17 & 18,68 \% \\
\text { PTB, PL, PPS, PDT, PP }\end{array}$ & $\begin{array}{cc}49 & 24,74 \% \\
\text { PPS, PSB, PTB, PDT, PP, } \\
\text { PL }\end{array}$ \\
\hline Pequenos & $\begin{array}{cc}11 & 32,35 \% \\
\text { PTC, PMN, PC do B, PRTB, PRP }\end{array}$ & $\begin{array}{lr}3 & 3,29 \% \\
\text { PMN, PRP, PC do B }\end{array}$ & $\begin{array}{cc}20 & 10,10 \% \\
\text { PSDC, PMN, PRONA, } \\
\text { PTC, PC do B, PRP, PSC, } \\
\text { PSL, PSDC, PT do B }\end{array}$ \\
\hline $\begin{array}{l}\text { Vereadores eleitos pelo } \\
\text { Partido do Prefeito }\end{array}$ & $\begin{array}{cc}10 & 29,41 \% \\
\text { PSB, PMDB, PDT, PTB, PSDB }\end{array}$ & $\begin{array}{lr}57 & 62,63 \% \\
\text { PMDB, PP, PFL, PT, } \\
\text { PSDB }\end{array}$ & $\begin{array}{cc}102 & 51,51 \% \\
\text { PFL, PPS, PT, PL, PDT, } & \text { PSDB, PMDB, PP, PTB }\end{array}$ \\
\hline Total & $32 \%$ & $44,82 \%$ & $198 \quad 36,66 \%$ \\
\hline $\begin{array}{c}\text { Total de vereadores } \\
\text { eleitos }\end{array}$ & 106 & 203 & 540 \\
\hline
\end{tabular}

Fonte: TSE - Tribunal Superior Eleitoral.

Em Alagoas, onde a competição partidária é maior e os pequenos partidos conseguem um número maior de cadeiras - ultrapassando os partidos maiores e os partidos do prefeito eleito -, os prefeitos de apenas 4 municípios (Penedo, São Luís do Quitute, Batalha e São Miguel dos Campos) não conseguiram eleger nenhum vereador. Em Santa Catarina, todos os prefeitos elegeram candidatos. Em São Paulo, apenas os prefeitos de dois municípios (Fernandópolis e Franca) não conseguiram eleger seus candidatos. Coincidentemente, é em Santa Catarina que a coligação do prefeito elege o maior número de vereadores.

Em Alagoas, os pequenos partidos foram beneficiados nas eleições proporcionais. Em Santa Catarina e em São Paulo, foram os médios partidos que obtiveram maior representação.

Os grandes partidos também não obtiveram vantagens eleitorais ao entrarem na coligação do prefeito, apesar da possibilidade de as coligações registrarem um número maior de candidatos.

Os dados obtidos mostram, que o partido do prefeito obtém a maior vantagem conseguindo eleger um número expressivo de vereadores (guardadas as exceções e levando-se em conta o tamanho do distrito eleitoral), numa estratégia montada visando a redução do risco de perder a eleição e a garantia de maioria na Câmara Municipal.

Partindo-se da premissa de que as coligações eleitorais são elementos importantes na estruturação do comportamento do legislativo municipal a questão a ser investigada é de como coligações 
eleitorais se transformam em coalizões governativas, num universo tão permeável aos interesses individualistas e pouco cooperativos de acordo com a literatura sobre o tema e onde a relação situação/oposição perpassa as identidades partidárias.

Mesmo considerando-se que a coalizão mínima vencedora, no jogo eleitoral, não é a mesma necessária para vencer no jogo governativo, as estratégias e as negociações da relação Executivo/Legislativo municipal vão sendo construídas no jogo eleitoral onde eleições majoritárias e proporcionais coincidem e onde o sistema partidário local exerce um papel importante na coordenação política.

O entendimento mais adequado de como funciona o sistema partidário local e o papel que exerce na relação Executivo/Legislativo contribuiria para uma melhor explicação de como as preferências políticas se distribuem entre os representantes locais e quais as consequências para a democratização do governo local.

\section{Bibliografia}

ABRUCIO, F. L.; COSTA, V. C. A redefinição do papel do Estado no âmbito local. São Paulo em Perspectiva, v. 10, n. 3, p. 3-143, 1996.

ALMEIDA, M. H. T.; CARNEIRO, L. P. Liderança local, democracia e políticas públicas no Brasil. Opinião Pública, v. 9, n. 1, p. 21-42, 2003.

AMES, B.. A organização partidária local nas eleições presidências de 1989. Dados, v. 37, n. 1, p. 5-42, 1994.

AMES, B. Os entraves da democracia no Brasil. Rio de Janeiro: FGV, 2003.

AMORIN NETO, O.; SANTOS, F. A conexão presidencial: facções pró e antigoverno e disciplina partidária no Brasil. Dados, v. 44, n. 2, p. 201-321, 2001.

ANASTACIA, F.; INÁCIO, M. Notas sobre coalizões políticas e democracia: diz-me com quem andas. Seminário Internacional Estudos sobre o Legislativo, UnB, Câmara dos Deputados. Brasília, setembro de 2007.

ANDRADE, R. de C. (Org) Processo de governo no município e no Estado. São Paulo: Edusp, 1998.

AVELINO FILHO, G. Cliente e política no Brasil, revisitando velhos problemas. Novos Estudos, n.38, p. 225-240, mar. 1994. 
ÁVILA FILHO, P. et al. Legislativo municipal e intermediação de interesses: notas de pesquisa. $4^{\circ}$ Encontro da ABCP, 2004. CD-Rom.

BOSCHI, R. Descentralização, clientelismo e capital social na governança urbana: comparando Belo Horizonte e Salvador. Dados, v. 42, n. 4, p. 569-808, 1999.

BRAGA, M. do S. Dinâmica de coordenação eleitoral em regime presidencialista e federativo: determinantes e consequências das coligações partidárias no Brasil. In: SOARES, G. A. D.; RENNÓ, L. R. (Org) Reforma política. Lições da história recente. Rio de Janeiro: FGV, 2006.

BRAGA, M. do S.; BORGES, T. D. P. Organização e poder nos partidos políticos brasileiros. $6^{\circ}$ Encontro da ABCP, 29.07.2008 a 01.08.2008. Campinas, SP.

BRASIL. Constituição da República Federativa do Brasil. 14. ed. Rio de Janeiro: DP \& A Editora, 2003 (Atualizada pelo EC 40).

CAETANO, B. Executivo e Legislativo na esfera local. Novos Estudos Cebrap, n. 71, p. 101125, mar. 2005.

CARNEIRO, L. P.; ALMEIDA, M. H. Tavares. Eleições para Câmaras Municipais, migrações partidárias e formação de governos: a constituição dos sistemas partidários locais no Brasil. Texto apresentado no XXIX Encontro Anual da ANPOCS, GT Estudos Legislativos, Caxambu, 2005.

CORADINI, O. L. Em nome de quem? Recursos Sociais no recrutamento de elites políticas. Rio de Janeiro: Relume Dumará, 2001.

COUTO, C. G. Negociação, decisão e governo: padrões interativos na relação ExecutivoLegislativo e o caso paulistano. In: ANDRADE, Régis de Castro (Org). Processo de governo no município e no Estado. São Paulo: Edusp, 1998.

DANTAS, H. Coligações nas eleições municipais de 2000 e 2004: a força do partido dos governadores. In: $6^{\circ}$ Encontro da ABCP, 29.07.2008 a 01.08.2008. Campinas, São Paulo

DOWNS, A. An economic theory of democracy. New York: Wiley, 1957.

FIGUEIREDO, A; LIMONGI, F. Executivo e Legislativo na nova ordem constitucional. Rio de Janeiro: FGV, 1999.

FIORINA, M. Congress Keytone of the Washington establishment. New Haven, Yale, University Press, 1989.

NETO, J. O Legislativo e o poder local. In: BENEVIDES, M. V. et al (Org). Reforma política e cidadania. São Paulo: Perseu Abramo, 2003.

KERBAUY, M. T. M. A morte dos coronéis: política interiorana e poder local. Araraquara: Laboratório Editorial/Unesp, 2000. 
KERBAUY, M. T. M. As Câmaras Municipais Brasileiras: perfil de carreira e percepção sobre o processo decisório local. Opinião Pública, v. 2, p. 337-365, 2005.

KERBAUY, M. T. M. Federalismo, descentralização e democracia. Estudos de Sociologia, v. 6, n. 10, p. 51-62, 2001.

KERBAUY, M. T. M. Legislativo Municipal, Partidos e Negociações Políticas. In: $6^{0}$ Encontro da ABCP, 29.07.2008 a 01.08.2008. Campinas, São Paulo

KINZO, M. D. Radiografia do sistema partidário brasileiro. São Paulo: Fundação Konrad Adenaures, 1993.

LAMOUNIER, B.; MENEGUELLO, R. Partidos políticos e consolidação democrática: o caso brasileiro. São Paulo: Brasiliense, 1986.

LAVAREDA, A. A democracia nas urnas: o processo partidário eleitoral brasileiro. Rio de Janeiro: Rio Fundo, 1991.

LEAL, V. N. Coronelismo, enxada e voto: o município e o regime representativo no Brasil. São Paulo: Alfa-Ômega, 1975.

LIMA JUNIOR, O. B. de. Os partidos políticos brasileiros: a experiência federal e regional (1945-1964). Rio de Janeiro: Graal, 1983.

MACHADO, C. A. M.; MIGUEL, L. F. Coerência, coesão e consistência: uma proposta de tipologia para coligações municipais. In: $6^{\circ}$ Encontro da ABCP, 29.07.2008 a 01.08.2008. Campinas, SP.

MAINWARING, S. P. Sistemas partidários em novas democracias. O caso do Brasil. Rio de Janeiro: FGV/Mercado Aberto, 2001.

MARENCO DOS SANTOS, A. dos. Nas fronteiras do campo político: raposas e outsiders no Congresso Nacional. Revista Brasileira de Ciências Sociais, n. 33, p. 87-101, 1997.

MELLO, M. A. Municipalismo, nation-building e a modernização do estado no Brasil. Revista Brasileira de Ciências Sociais, n.23, p. 8-100, 1993.

MELO, M. A. Instituições orçamentárias municipais e o processo legislativo em Recife - 19882000. In: LUBAMBO, C.; et al (Org) Desenho institucional e participação política: experiências no Brasil Contemporâneo. Rio de Janeiro: Vozes, 2005.

MENEGUELO, R. Partidos e governo no Brasil contemporâneo (1985-1997). São Paulo: Paz e Terra, 1998.

MESSEMBERG, D. A elite parlamentar do pós-constituinte: atores e práticas. São Paulo: Brasiliense, 2002. 
NICOLAU, J. M. Multipartidarismo e democracia: um estudo sobre o sistema partidário brasileiro (1985-1994). Rio de Janeiro: FGV, 1996.

NOLL, M. I.; LEAL, C. S. A política local na construção da carreira política: o caso dos vereadores (São Paulo, Fortaleza e Porto Alegre). In: 6º Encontro da ABCP, 29.07.2008 a 01.08.2008. Campinas, SP.

NUNES, E. A gramática política no Brasil. Clientelismo e insulamento democrático. Rio de Janeiro: Zahar, 1999.

PEREIRA, C.; RENNO, L. O que é que o reeleito tem? Dinâmicas político-institucionais locais e nacionais nas eleições de 1998 para a Câmara dos Deputados. Dados, v. 44, n. 2, p. 323-362, 2001.

PRALON, E. M.; FERREIRA, G. N. Centralidade da Câmara Municipal de São Paulo no processo decisório. In: ANDRADE, R. de C. (Org) Processo de governo no município e no Estado. São Paulo: Edusp, 1998.

RODRIGUES, L. M. Partidos, ideologia e composição social: um estudo das bancadas na Câmara dos Deputados. São Paulo: Edusp, 2002.

SAMUELS, D. Financiamento de campanha e eleições no Brasil. In: BENEVIDES, M. V. et al (Org) Reforma política e cidadania. São Paulo: Fundação Perseu Abramo, 2003. p. 364-291.

SANTOS, F. (Org) O poder Legislativo nos estados: diversidade e convergência. Rio de Janeiro: FGV, 2001.

SANTOS, F. Deputados federais e instituições legislativas no Brasil - 1946-99. In: BOSCHI, Renato; DINIZ, E.; SANTOS, F. Elites políticas e econômicas no Brasil contemporâneo. São Paulo: Fundação Konrad Adenauer, 2000.

SANTOS, F. Microfundamentos do clientelismo político no Brasil 1959-1963. Dados, v. 38, n. 3, p. 459-496, 1995.

SANTOS, M. L. Teoria e método nos estudos sobre o legislativo no Brasil: uma revisão da literatura no período 1995-2005. In: $6^{\circ}$ Encontro da ABCP, 29.07.2008 a 01.08.2008. Campinas, SP.

SETZLER, M. Democratizing urban Brazil: institucional legacies and determinants of accountability in local elections and legislatures. Paper presented at the Lasa, Miami, 2000.

SOARES, G. A. D. Sociedade e política no Brasil. São Paulo: Difel, 1973.

SOUZA, M. do C. Campello de. Estado e partidos políticos no Brasil (1930-1964). São Paulo: Alfa-Ômega, 1990. 
SOUZA, R. B. Clientelismo e voto na Califórnia fluminense. 28 Encontro Anual da Anpocs. Caxambu, 2004. CD Rom.

TEIXEIRA, M. A. C. Clientelismo e voto na cidade de São Paulo 1993/1999: uma análise das relações Executivo Legislativo e seus impactos no sistema políticos local. Dissertação de Mestrado em Ciências Sociais. Pontifícia Universidade Católica: São Paulo, 2000.

Artigo recebido em 18 /08/2008. Aprovado em 23/10/2008. 